\title{
KUALITAS HIDUP PENDERITA KANKER SERVIKS BERDASARKAN JUMLAH KOMORBID, KOMPLIKASI PENYAKIT DAN EFEK SAMPING KEMOTERAPI
}

\author{
${ }^{1}$ Suwendar, ${ }^{2}$ Achmad Fudholi, ${ }^{2}$ Tri Murti Andayani, ${ }^{3}$ Herri S. Sastramihardja \\ ${ }^{1}$ Program Studi Farmasi Fakultas MIPA Universitas Islam Bandung \\ ${ }^{2}$ Fakultas Farmasi Universitas Gadjah Mada \\ ${ }^{3}$ Fakultas Kedokteran Universitas Padjadjaran \\ email : ${ }^{1}$ suwendarsuwendar48@gmail.com
}

\begin{abstract}
ABSTRAK
Pendahuluan: Kanker serviks merupakan jenis kanker dengan prevalensi tinggi. Kualitas hidup penderita menurun disebabkan penyakitnya maupun terapi yang diberikan. Komorbid, komplikasi dan efek samping kemoterapi mempengaruhi kualitas hidup pasien. Tujuan: Penelitian bertujuan mengetahui pengaruh jumlah komorbid, komplikasi dan efek samping kemoterapi terhadap kualitas hidup pasien. Metode Penelitian: Penelitian dilakukan dengan rancangan cross sectional prospektif. Subyek penelitian adalah pasien kanker serviks rawat inap yang memenuhi kriteria inklusi (74 orang). Data berupa kualitas hidup berdasarkan jumlah komorbid, komplikasi dan efek samping kemoterapi. Pengumpulan data dilakukan menggunakan kuesioner EQ-5D-3L. Data dianalisis dengan uji ANOVA ( $p<0,05)$. Hasil : Pada pasien tanpa komorbid, dengan satu dan dua komorbid : nilai utility masing-masing adalah $0,67 \pm 0,13,0,55 \pm 0,15$ dan $0,46 \pm 0,16$; nilai EQ-5D VAS masing-masing adalah $57,50 \pm 24,75 ; 45,45 \pm 9,34$ dan $40,00 \pm 8,16$. Komplikasi yang paling sering dijumpai adalah anemia. Anemia berat lebih menurunkan kualitas hidup dibandingkan anemia ringan meskipun tidak signifikan. Untuk pasien dengan anemia ringan dan berat, nilai utility masing-masing adalah : 0,64 $\pm 0,14$ dan $0,48 \pm 0,15$, sedangkan nilai EQ-5D VAS masingmasing adalah : 46,67 $\pm 14,15$ dan 42,50 $\pm 15,12$. Efek samping kemoterapi yang paling sering dialami adalah emesis dan trombositopenia. Kualitas hidup penderita dengan trombositopenia lebih rendah dibandingkan dengan pasien yang mengalami emesis, meskipun tidak signifikan. Pada pasien yang mengalami emesis, nilai utility adalah $0,65 \pm 4,28$ dan nilai EQ-5D VAS adalah 49,54 $\pm 15,43$. Pada pasien dengan trombositopenia, nilai utility adalah $0,43 \pm 0,38$ dan nilai EQ-5D VAS adalah 35,00 $\pm 13,23$. Kesimpulan : Jika jumlah komorbid yang diderita pasien kanker serviks semakin banyak serta komplikasi penyakit dan efek samping kemoterapi makin berat maka kualitas hidup pasien akan semakin menurun.
\end{abstract}

Kata Kunci: Kanker serviks, kualitas hidup, EQ-5D-3L

\begin{abstract}
Background: Cervical cancer is a type of cancer with a high prevalence. The quality of life will decrease due to the disease or the therapy given. The presence of comorbidities, complications and side effects of chemotherapy that accompany will affect the quality of life. Aims: This study aimed to determine the effect of comorbid amount, complications and side effects of chemotherapy on the quality of life of patients. Methods: The study was conducted in a prospective cross-sectional design. The subjects of the study were hospitalized patients who met the inclusion criteria ( 74 patients). The data taken were the quality of life based on the number of comorbidities, complications and side effects of chemotherapy suffered. Data collection was carried out using the EQ-5D-3L questionnaire. Data were analyzed by ANOVA test $(\mathrm{p}<0.05)$. Results: In patients without comorbidities, with one comorbid and two comorbid: the utility value was $0.67 \pm 0.13,0.55 \pm 0.15$ and 0.46
\end{abstract}


\pm 0.16 ; the EQ-5D VAS were $57.50 \pm 24.75 ; 45.45 \pm 9.34$ and $40.00 \pm 8.16$ respectively. The most common complication was anemia. Severe anemia reduced quality of life compared to mild anemia, although not significant. For patients with mild and severe anemia, the utility values were: $0.64 \pm 0.14$ and $0.48 \pm 0.15$, while the EQ-5D VAS values were: $46.67 \pm 14.15$ and $42.50 \pm 15.12$ respectively. The most common side effects of chemotherapy were emesis and thrombocytopenia. The quality of life of patients with thrombocytopenia was lower compared to patients with emesis, although not significantly. In patients who experience emesis, the utility value was $0.65 \pm 4.28$ and the EQ-5D VAS was $49.54 \pm 15.43$. In patients with thrombocytopenia, the a utility value was $0.43 \pm 0.38$ and the EQ-5D VAS was $35.00 \pm 13.23$. Conclusion: If the number of comorbidities suffered by patients with cervical cancer is increasing, in the other hand the complications of the disease and the side effects of chemotherapy are getting heavier, then the patient's quality of life will decrease.

Keywords: Cervical cancer, quality of life, EQ-5D-3L

\section{PENDAHULUAN}

Salah satu jenis kanker dengan jumlah penderita yang tinggi di Indonesia adalah kanker serviks (KPKN, 2015). Selain outcome klinik, salah satu aspek yang juga penting untuk dievaluasi dalam menilai efektivitas pengobatan kanker serviks adalah outcome humanistik berupa kualitas hidup pasien. Gambaran kualitas hidup pasien kanker serviks sebelum menerima terapi merupakan hal yang sangat penting karena merupakan acuan kondisi awal untuk mengevaluasi keberhasilan terapi dengan membandingkannya dengan kualitas hidup setelah terapi. Pasien seringkali tidak hanya menderita kanker serviks, namun juga menderita satu atau lebih komorbid (penyakit penyerta). Adanya komorbid yang diderita berpotensi mempengaruhi kualitas hidup pasien kanker serviks saat sebelum mendapatkan kemoterapi. Penderita kanker serviks juga sering menderita komplikasi penyakit. Komplikasi penyakit ini juga berpotensi mempengaruhi kualitas hidup pasien. Kemoterapi merupakan salah satu upaya terapi pada kanker serviks. Kemoterapi menimbulkan efek samping yang juga dapat mempengaruhi kualitas hidup pasien (Endarti et al, 2015 dan Perwitasari et al, 2011). Salah satu cara untuk mengukur kualitas hidup adalah dengan menggunakan kuesioner EQ-5D-3L. Kuesioner ini merupakan alat ukur kualitas hidup pasien untuk memperoleh nilai indeks EQ-5D (Thavorncharoensap et al, 2014).

Berdasarkan paparan di atas, masalah yang dikaji dalam penelitian ini adalah berapa nilai EQ-5D VAS dan nilai indeks EQ-5D (utility) pasien kanker serviks : yang tanpa komorbid, menderita satu serta dua komorbid; pada pasien dengan komplikasi yang paling banyak diderita serta pada pasien dengan efek samping yang paling banyak diderita. Tujuan penelitian ini adalah menetapkan nilai EQ-5D VAS dan indeks EQ-5D pada pasien yang tanpa komorbid, menderita satu dan dua komorbid, menderita komplikasi dan efek samping 
yang paling banyak diderita. Hasil penelitian ini diharapkan memberikan manfaat berupa diperolehnya data nilai EQ-5D VAS dan indeks EQ-5D yang didapat dijadikan sebagai baseline untuk penentuan dan evaluasi jenis terapi pada penderita kanker serviks.

\section{METODE PENELITIAN}

Penelitian ini merupakan jenis penelitian non eksperimental yang bersifat analitik. Penelitian dilakukan dengan menggunakan rancangan cross sectional. Data diambil secara prospektif dengan melakukan observasi lapangan. Penelitian dilakukan di RSUP Dr. Hasan Sadikin Bandung. Data yang digunakan adalah data pasien yang diperoleh dari rekam medis dari bulan Juni 2015 sampai Maret 2016. Populasi adalah pasien penderita kanker serviks rawat inap RSUP Dr. Hasan Sadikin Bandung kelas perawatan 1, 2 dan 3 yang memenuhi kriteria inklusi. Kriteria inklusi meliputi: pasien rawat inap peserta Jaminan Kesehatan Nasional (JKN), diagnosis utama kanker serviks dengan atau tanpa penyakit penyerta, pasien dengan kriteria stadium kanker yang mendapatkan pilihan terapi dengan kemoterapi, baik untuk tujuan kuratif, kontrol, paliatif atau dalam bentuk kombinasi dengan terapi lain (stadium I sampai IV), memiliki kelengkapan data rekam medik dan rincian biaya perawatan, pasien kanker serviks yang pertama kali menjalani kemoterapi dan pasien kanker serviks yang menjalani absolut satu siklus kemoterapi. Kriteria eksklusi meliputi pasien pindahan dari rumah sakit lain, pasien waktu pulang meninggal dunia sebelum menjalani tiga siklus kemoterapi dan status pasien "keluar" atas permintaan sendiri (APS), sehingga pasien tidak sepenuhnya menjalani perawatan yang diberikan rumah sakit.

Pada penelitian ini dilakukan evaluasi kualitas hidup pasien kanker serviks berdasarkan jumlah comorbid, komplikasi penyakit dan efek samping kemoterapi yang terjadi. Evaluasi kualitas hidup dilakukan dengan menggunakan kuesioner EQ-5D-3L (EuroQoL-5 Dimensions-3 Levels) versi Bahasa Indonesia untuk mendapatkan nilai EQ- 5D VAS dan indeks EQ-5D (Suwendar dkk, 2017). Data dari hasil pengisian kuesioner tersebut diolah dengan menggunakan value set yang berlaku di negara Malaysia (Yusof et al, 2012) berhubung di Indonesia belum ada value set untuk kuesioner EQ-5D-3L. Evaluasi kualitas hidup berdasarkan jumlah komorbid dan komplikasi penyakit dilakukan sebelum pasien menjalani kemoterapi. Evaluasi kualitas hidup berdasarkan efek samping kemoterapi dilakukan setelah pasien mendapatkan kemoterapi siklus pertama. Data yang diperoleh dianalisis secara statistik menggunakan uji $\mathrm{t}$ dengan nilai $\mathrm{p}<0,05$. 


\section{HASIL DAN PEMBAHASAN}

Jumlah pasien kanker serviks yang menjalani perawatan di RSUP Dr. Hasan Sadikin Bandung dari bulan Juni 2015 sampai Maret 2016 adalah sebanyak 110 orang. Sebanyak 13 orang pasien tidak menggunakan kemoterapi dalam penatalaksanaan penyakitnya dan 97 orang pasien menjalani kemoterapi. Dari 97 orang pasien tersebut 23 orang diekslusi karena empat orang merupakan pindahan dari rumah sakit lain, delapan orang tidak selesai menjalani tiga siklus kemoterapi dan 11 orang tidak bersedia dilibatkan dalam penelitian ini. Dari delapan orang pasien yang tidak selesai menjalani tiga siklus kemoterapi tersebut, dua orang pasien berhenti menjalani terapi atas permintaan sendiri (APS), tiga orang karena tidak datang kembali untuk menjalani terapi (drop out) dan tiga orang meninggal dunia sebelum selesai menjalani tiga siklus kemoterapi. Dengan demikian jumlah pasien yang dilibatkan dalam penelitian ini adalah sebanyak 74 orang.
Tabel 1. Data Demografi Pasien Kanker Serviks yang Mendapat Kemoterapi di RSUP Dr. Hasan Sadikin Bandung

\begin{tabular}{|c|c|c|}
\hline Demografi pasien & $\mathbf{n}$ & $\%$ \\
\hline \multicolumn{3}{|l|}{ Umur dalam tahun } \\
\hline$<45$ & 21 & 28,4 \\
\hline $45-64$ & 53 & 71,6 \\
\hline$\geq 65$ & 0 & 0 \\
\hline $\begin{array}{l}\text { Rata-rata umur } \\
\text { (SD) }\end{array}$ & \multicolumn{2}{|c|}{$47,6 \pm 8,6$} \\
\hline Kisaran Umur & \multicolumn{2}{|c|}{$21-62$} \\
\hline \multicolumn{3}{|l|}{ Tingkat pendidikan } \\
\hline Lulusan SD & 28 & 37,8 \\
\hline Lulusan SMP & 17 & 23,0 \\
\hline Lulusan SLTA & 27 & 36,5 \\
\hline Sarjana & 2 & 2,7 \\
\hline \multicolumn{3}{|l|}{ Paritas } \\
\hline Rata-rata & \multicolumn{2}{|c|}{$2,6 \pm 1,4$} \\
\hline \multicolumn{3}{|l|}{ Stadium } \\
\hline I & 12 & 16,2 \\
\hline II & 33 & 44,6 \\
\hline III & 25 & 33,8 \\
\hline IV & 4 & 5,4 \\
\hline \multicolumn{3}{|l|}{ Kelas perawatan } \\
\hline Kelas I & 6 & 8,1 \\
\hline Kelas II & 10 & 13,5 \\
\hline Kelas III & 58 & 78,4 \\
\hline
\end{tabular}

Data demografi pasien yang menjadi subyek penelitian ini dicantumkan pada Tabel 1. Sebagian besar pasien berada pada rentang usia antara 45-64 tahun dengan ratarata usia 47,6 68,6 tahun. Hasil penelitian di RSUP Dr. Hasan Sadikin Bandung sebelumnya (Irvianty dan Sukarya, 2011) menunjukkan bahwa tidak ada hubungan antara usia dengan prevalensi kanker serviks.

Pasien yang yang menjadi subjek penelitian ini sebagian besar dengan latar belakang pendidikan di bawah SLTA $(60,8 \%)$. Tingginya kasus pada pasien dengan tingkat pendidikan rendah juga sejalan dengan hasil penelitian di RSUP Dr. Hasan Sadikin sebelumnya, yaitu tingkat 
kejadian pasien dengan lama Pendidikan $\leq$ enam tahun mencapai $71,7 \%$ dari 46 pasien yang diteliti. Hasil penelitian tersebut menunjukkan bahwa terdapat hubungan yang bermakna antara kejadian kanker serviks dengan tingkat pendidikan pasien. Pasien dengan lama pendidikan kurang dari enam tahun lebih beresiko terkena kanker serviks (Irvianty dan Sukarya, 2011).

Berdasarkan tingkat keparahan penyakit yang diderita, sebagian besar pasien berada pada stadium II. Dari total 74 pasien kanker serviks yang dilibatkan dalam penelitian ini, 33 orang berada pada stadium II $(44,6 \%)$.

Tabel 2. Nilai EQ-5D VAS dan Indeks EQ-5D Berdasarkan Jumlah Comorbid, Komplikasi Kanker Serviks dan Efek Samping Kemoterapi

\begin{tabular}{lccrcc}
\hline \multicolumn{1}{c}{ Kondisi } & $\mathbf{n}$ & \multicolumn{2}{c}{ Nilai EQ-5D VAS } & \multicolumn{2}{c}{ Nilai indeks EQ-5D } \\
\cline { 3 - 6 } & & Rata-rata & s.d. & Rata-rata & s.d. \\
\hline Comorbid & 54 & 57,50 & 24,75 & 0,67 & 0,13 \\
$\quad$ Tanpa comorbid & 11 & 45,45 & 9,34 & 0,55 & 0,15 \\
$\quad \begin{array}{l}\text { 1 comorbid } \\
\text { 2 comorbid }\end{array}$ & 9 & 40,00 & 8,16 & 0,46 & 0,16 \\
Komplikasi & & & & & \\
$\quad$ Anemia ringan & 41 & 46,67 & 14,15 & 0,64 & 0,14 \\
$\quad$ Anemia berat & 33 & 42,50 & 15,12 & 0,48 & 0,15 \\
Efek samping & & & & & \\
$\quad$ Emesis & 74 & 49,54 & 15,43 & 0,65 & 0,17 \\
$\quad$ Trombositopenia & 3 & 35,00 & 13,23 & 0,43 & 0,28 \\
\hline Keterangan : n keseluruhan $=74$ & & & &
\end{tabular}

Hasil evaluasi dicantumkan pada Tabel 2. Berdasarkan data pada Tabel 2, dapat dilihat bahwa nilai EQ-5D VAS dan nilai indeks EQ-5D pasien yang menderita satu comorbid dan dua comorbid lebih rendah dibandingkan dengan pasien tanpa comorbid. Pasien dengan dua comorbid memiliki nilai EQ-5D VAS dan indeks EQ5D lebih rendah dibandingkan dengan pasien dengan satu comorbid. Hal ini menunjukkan bahwa jika jumlah comorbid yang diderita pasien makin banyak, cenderung akan menurunkan status kesehatan pasien.
Tabel 2 juga mencantumkan komplikasi penyakit dan efek samping dari penggunaan obat kemoterapi (masingmasing dua jenis dengan jumlah penderita terbanyak). Komplikasi berupa gangguan hematologik merupakan kondisi yang paling sering dijumpai pada pasien setelah mendapatkan kemoterapi. Dalam penelitian ini, pada pasien kanker serviks ternyata mayoritas menderita anemia, baik berat maupun ringan. Evaluasi dilakukan sebelum pasien mendapatkan kemoterapi. Kondisi anemia berat menunjukkan nilai EQ-5D VAS dan indeks kesehatan yang lebih rendah dibandingkan dengan anemia ringan. 
Hal ini menunjukkan bahwa keparahan anemia cenderung mempengaruhi status kesehatan pasien. Makin berat kondisi anemia, akan makin menurunkan fungsi kognitif dan meningkatkan gejala kelelahan (Medina dan Fausel, 2008 dan Tunas dkk, 2016), sehingga kualitas hidup pasien akan semakin menurun.

Efek samping obat kemoterapi dievaluasi setelah pasien mendapatkan kemoterapi siklus pertama. Efek samping paling sering yang dialami oleh pasien saat mendapatkan kemoterapi dalam penelitian ini adalah emesis. Hal ini karena penggunaan cisplatin dan carboplatin yang memiliki daya emetogenik tinggi, dengan daya emetogenik cisplatin lebih kuat daripada carboplatin (Hilarius et al, 2012). Pada pasien yang menggunakan carboplatin juga muncul efek samping berupa trombositopenia. Hal ini karena carboplatin memiliki efek myelosupresiva yang berdampak pada hambatan pembentukan trombosit (Ten Berg et al, 2011). Emesis merupakan kondisi dengan nilai EQ-5D VAS dan nilai indeks EQ-5D yang lebih tinggi dibandingkan dengan trombositopenia. Hal ini terjadi karena penggunaan obat-obat antiemesis yang efektif menekan gejala mual dan muntah yang merupakan efek samping kemoterapi. Nilai EQ-5D VAS pasien yang mengalami emesis berdasarkan hasil penelitian di Amerika Serikat adalah $\leq 70$ untuk kondisi ringan dan $\leq 60$ untuk kondisi berat (Basch et al., 2009). Berdasarkan hasil penelitian ini terlihat bahwa kondisi pasien sesaat setelah pemberian kemoterapi siklus pertama berada pada kondisi emesis yang berat. Nilai EQ-5D VAS dan indeks EQ-5D pasien yang mengalami trombositopenia cenderung lebih rendah dibandingkan dengan emesis. Hal ini terjadi karena dampak dari trombositopenia yang jauh lebih berat dibandingkan dengan emesis yaitu meningkatkan gejala pendarahan (Tortora and Derrickson, 2006).

\section{KESIMPULAN}

Jika jumlah komorbid yang diderita pasien kanker serviks semakin banyak serta komplikasi penyakit dan efek samping kemoterapi makin berat maka kualitas hidup pasien akan semakin menurun. Nilai EQ-5D VAS pasien tanpa komorbid, dengan satu komorbid an dua komorbid masing-masing adalah 57,50 $\pm 24,75,45,45 \pm 9,34$ dan 40,00 $\pm 8,16$ sedangkan nilai indeks EQ-5D masing-masing $0,67 \pm 0,13,0,55 \pm 0,15$ dan $0,46 \pm 0,16$. Anemia merupakan komplikasi yang paling sering dijumpai pada pasien setelah mendapatkan kemoterapi. Keparahan anemia cenderung mempengaruhi status kesehatan pasien. Nilai EQ-5D VAS pasien yang menderita anemia ringan dan berat masing-masing adalah 46,67 $\pm 14,15$ dan 42,50 \pm 15,12, sedangkan nilai indeks EQ-5D masingmasing 0,64 $\pm 0,14$ dan $0,48 \pm 0,15$. Dua 
jenis efek samping paling sering yang dialami oleh pasien saat mendapatkan kemoterapi dalam penelitian ini adalah emesis dan trombositopenia dengan nilai EQ-5D VAS masing-masing sebesar 49,54 \pm 15,43 dan $35,00 \pm 13,23$ serta nilai indeks EQ-5D pasien masing-maing sebesar 0,65 \pm 4,28 dan $0,43 \pm 0,38$.

\section{UCAPAN TERIMA KASIH}

Ucapan terima kasih disampaikan kepada :

1. Direktur RSUP Dr. Hasan Sadikin Bandung yang telah memberikan ijin kepada peneliti untuk melakukan penelitian

2. Komite Etik Penelitian Medis dan Kesehatan Fakultas Kedokteran Universitas Gadjah Mada yang telah memberikan rekomendasi penelitian berupa ethical approval no: KE/FK/426/EC

3. EuroQoL Research Foundation yang telah mengirimkan kuesioner kesehatan EQ-5D-3L versi Bahasa Indonesia untuk dipergunakan dalam penelitian ini.

\section{DAFTAR PUSTAKA}

Endarti D, Riewpaiboon A, Thavorncharoensap M, Prafitsitthikorn N, Hutubessy, R and Kristina SA, 2015. Evaluation of Health-Related Quality of Life Among Patients with Cervical Cancer in Indonesia, Asian Pacific Journal of Cancer Prevention, 16: 33453350

Hilarius DL, Kloeg PH, van der Wall E, van den Heuvel, JJG, Gundy CM and Aaronson NK, 2012. Chemotherapyinduced nausea and vomiting in daily clinical practice: a community hospitalbased study, Supportive Care in Cancer, 20:107-117.

Irvianty A dan Sukarya WS, 2011. Hubungan Karakteristik Pasien dengan Kejadian Kanker Serviks yang Dirawat Inap di Bagian Obstetri Ginekologi Rumah Sakit Hasan Sadikin Bandung Periode 1 Januari 2010 - 31 Desember 2010, Prosiding SNaPP 2011 Sains Teknologi dan Kesehatan, 2(1): 47-54

Komite Nasional Penanganan Kanker (KPKN), 2015. Panduan Pelayanan Klinis Kanker Serviks, Kementerian Kesehatan Republik Indonesia, Jakarta, 1.

Medina PJ and Fausel C, 2008. Cancer Treatment and Chemotherapy, in Dipiro, JT, Talbert RL, Yee GC, Matzke GR, Wells, BG and Posey, LM, Pharmacotherapy a Pathopahysiologic Approach, $7^{\text {th }}$ ed, McGraw Hill Medical, New York:2112-2113.

Suwendar, Fudholi A, Andayani TM, dan Sastramihardja HS, 2017. Evaluasi Kualitas Hidup dengan EQ-5D pada Pasien Kanker Serviks Rawat Inap Sebelum dan Setelah Kemoterapi, Jurnal Farmasi Klinik Indonesia, 6(1): 1-10.

Ten Berg MJ, van den Bert PMLA, Shantakumar S, Bennet D, Voest EE, Huisman A and van Solinge WW, 2011. Thrombocytopenia in Adult Cancer Patients Receiving Cytotoxic Chemotherapy, Drug Safety, 34(12): 1151-1160

Thavorncharoensap M, 2014. Measurement of Utility, Journal of Medical Association of Thailand, 97: Suppl.5.

Tunas IK, Yowani SC, Indrayathi PA, Noviyani R dan Budiana ING, 2016. Penilaian Kualitas Hidup Pasien Kanker Serviks dengan Kemoterapi PaklitakselKarboplatin di RSUP Sanglah, Jurnal Farmasi Klinik Indonesia, 5(1): 35-46.

Yusof FAM, Goh A and Azmi S, 2012. Estimating an EQ-5D Value Set for Malaysia Using Time Trade-Off and Visual Analogue Scale Methodes, Value in Health, 15: 585-590. 